\title{
Analysing the Decoy Effect on Online Product Purchasing Preference:
}

\author{
An Experimental Study
}

\author{
Intan Sherlin*, Ferry Siswadhi \\ Economic Development and Management Study Program \\ Sekolah Tinggi Ilmu Ekonomi Sakti Alam Kerinci \\ Sungai Penuh, Indonesia \\ *intansvsi@gmail.com, fsiswadhi@stie-sak.ac.id
}

\author{
Elex Sarmigi \\ Shariah Banking Department \\ Institut Agama Islam Negeri (IAIN) Kerinci \\ Sungai Penuh, Indonesia \\ elexsarmigi@gmail.com
}

\begin{abstract}
Why would one want to buy expensive popcorn at the cinema, while they could get the same with much lower price in supermarket? Economically speaking, it is a rip off. However, there is an effective psychological technique called the decoy effect that could affect our economical thinking in a way that the targeted good will be purchased even if it is overpriced. Earlier research showed that consumer's preference could be shifted when there are three options: the target, competitor, and decoy. In this IR 4.0, sellers' market their products through digital marketplaces to reach more consumers worldwide. This research analyses whether the decoy effect exists in Indonesia's digital marketplace, and what effect does customers' review has on it. Data are collected through online surveys by replicating an online shopping choice sets for a trash bin. We choose marketplace Shopee as it has some features enabling us to do the experiment. The control and treatment 1 choice-sets are used to test whether the decoy effect exists in digital market. Treatment 2 is used to measure the strength of a decoy with smaller/bigger amount of buyers, and Treatment 3 measures the strength of a decoy with positive/negative reviews. A total of 90 subjects are randomly given one choice-set. Results show that decoy effect exists in digital marketplace Shopee. Amount of buyers influences the strength of the decoy effect; smaller amount weakened it, bigger amount strengthen it. Data also suggests that decoy with negative review reduces the strength of its effect, vice versa.
\end{abstract}

Keywords: decoy effect, decoy marketing, marketing strategy, purchasing preference, customer preference

\section{INTRODUCTION}

It is very interesting to study why we often makes irrational choices every day without even knowing it. The decoy effect says it all. Imagine if you are going to watch a cinema with your spouse and want to buy popcorns. You look at the first sight that a small-sized popcorn price is Rp. 30.000,- which is already expensive enough compared to ones being sold in the supermarket; while the large-sized popcorn price is Rp. $50.000,-$. In your mind you think, well perhaps the small one would be enough as it is quite pricey the popcorn here. Then you look a little bit closely and found that they also have an offer of a regular-sized popcorn for Rp. 45.000,-. Your mind starts to rethink, well, how come the price for a regular-sized is almost the same as the large one! So, by buying the large-sized popcorn, I could save more money than buying two small ones! (You think). Thus, you make up your mind and end up with buying the large-sized popcorn instead of just a small one like you previously decide. The silver lining is, you can't even finish that large popcorn till the movie ends. Isn't that story familiar? Well, we often times end up with something we don't really need rather than just buying what we actually need. And that is the power of decoy marketing.

\section{THEORETICAL REVIEW}

\section{A. Marketing Strategy Now and Then}

Acting as a company, to market our product, of course we need to have some strategy. Especially in this digital market where change is the only thing that constantly happening. Behavioural decision theory has shown that preferences are instable as well. Modern consumer has broader set of expectations and needs. Instead of heading to a store, speaking with a salesman and continue making a purchase, buyers nowadays have new, exciting channels to explore on their journey. Ones could use their smartphone to visit a store and browse an item, they could also research on its prices and solicit feedback/review from friends on social media or marketplaces, all before they decide to finally make a purchase.

There are different types of marketing strategies that are currently being employed by organizations to attract new customers as mentioned in Anastasia [1]:

- Cause Marketing: this strategy is getting more face time, as more and more consumers are integrating social responsibility in their purchasing decisions. Brands that prove themselves to be socially responsible are likely to catch the attention of customers and establish brand awareness and loyalty.

- Digital Marketing: this is used to describe the strategy of promoting brands or products through electronic media. It basically advocates the use of various digital devices and technologies to deliver marketing messages to customers.

- Event Marketing: this involves the development and execution of a promotional campaign that revolves 
around, or is closely linked to a special occasion or event. The themed activities entail face-to-face or inperson engagement and interaction, turning customers into active participants in the campaign.

- Engagement/Experiential Marketing: the focus is on making a strong connection between the brand and customers by "engaging" them directly, through active and participative interaction. Its principles are rooted in the reality that more and more people are learning not to believe anything they just hear about, or see in advertisements and promotional materials.

- PR Marketing: it entails the business developing and cultivating a relationship with the media or the press to create brand awareness in the market. This relationship will then allow the business to make use of the news or the business press, for example, to talk positively about the company, its products and services, and the reasons why consumers should also buy from them.

- Social Media Marketing: this is seen by many businesses to provide the most effective results, as establishing a strong social media presence will be beneficial to their branding and overall business success. Certainly, social media is considered to be the best platform for businesses to create and maintain brand awareness, as well as bring attention to new product/service launched/introduced. So far, business most commonly use these social media platforms: Facebook, LinkedIn, Twitter, Instagram, YouTube.

- Transactional Marketing: this is applied when businesses entice customers and encourage them to buy their products and services by offering discounts, coupons, and other incentives to buy. Holding a sale event, for example, is a classic example of an activity under this strategy.

- Word-of-Mouth (WoM) Marketing: this is described as an unpaid form of advertising, where satisfied customers promote the brand or product by telling other people how much they like or enjoy the offering. Highly satisfied customers are sure to recommend the products, services, or brands that they enjoy to other people; it means more new customers for the business.

\section{B. Digital Marketing and Electronic Word-of-Mouth}

There is a situation where customers often look for social proof: online shopping. When customers shop online through digital marketplace, they in this case face uncertainty, as the amount of information that is available to them online is limited and asymmetrical. Seller has more knowledge about product quality while buyers can only see what seller wrote on the product description, pictures and products review if available. Compare to the in-store customers, they are actually able to assess the quality of the product by directly touch or even try the product; while online customers can only rely on their visual assessment [2]. Evaluating a product through the internet is much more difficult since its interface cannot perfectly convey the product's characteristics.
Sometimes, customers as buyers would try to minimize uncertainty, due to asymmetric information, by trying to find social proof online. This could be done when they look for things in the marketplace, as marketplace has an adopted forms of social proof online called product/shop/seller ratings and reviews. This online ratings and revise as electronic word of mouth (eWOM) [3]. Various studies have shown that eWOM can cause a change of sales, both positive and negative by influencing consumers [4].

Indonesia's leading online marketplaces such as Shopee, and Tokopedia allow customers to post their reviews of on their apps/websites. Customers can rate the product, the seller, or the service, and give comments if necessary. Shopee, for example, use a star ratings to allow reviewers the opportunity to rate by numerical rating, ranging from one to five starts, from lowest to highest rating, consecutively. A one star rating is considered a very low rating and indicates an extremely negative view of the product, whereas five stars are given for a very high rating and reflects an extremely positive view of the product. The middle ground, a three-star rating, reflects a moderate view [4].

Star ratings are used by online shop owners/retailers to influence their products' probability of purchase. As shown in previous research conducted by Resnick and Zeckhauser [5] on eBay, and Chevalier [4], clearly review ratings reflect a form of social proof, thus consequently have strength to influence customer's purchasing decisions.

After buying a product, for sure consumers can either be satisfied or dissatisfied with their purchase; or to some extent, being indifferent. Hennig-Thurau [6] suggests that the level of satisfaction or dissatisfaction decides whether the consumer wants to create electronic Word-of-Mouth (eWOM) and if it is positive or negative. A consumer who is dissatisfied with their purchase will create negative eWOM out of concern for others or because they expect that their complaint will not be responded to properly by the seller [3]. Hennig-Thurau [7] also show that $44 \%$ of consumer who had read negative information/review would not buy a product after reading whereas only $28 \%$ of consumers who had read positive information/review would buy the product. Similar research about star ratings was conducted by Chevalier [4] and they found that the impact of 1-star reviews was greater than the impact of 5-star reviews.

\section{The Decoy Effect}

An important challenge for marketers now is to predict how introducing a new product can influence existing market shares. By modelling choice behaviour, marketers are able to tackle this issue. Models used to predict choice behaviour, such as Luce's choice model formulated by Luce [8], states that the probability of selecting an item over another from a pool of many items is not affected by the presence or absence of other items in the pool. Thus, adding new item to choice set cannot increase the probability of choosing an item of the original set. This condition is called the regularity condition and is crucial for the validity of Luce's choice model [9]. However, Huber [10] provided evidence that this important assumption of regularity can be violated by adding asymmetrically dominated alternative: a decoy [3]. 
Quoting Ariely on his TED talk, he says "The option that The decoy effect was first identified by Huber [9] and has been replicated in a wide variety of choice situations, involving both commercial products, as well as non-commercial products such as gambling, jobs and politics [3]. The decoy effect describes what happens when, while choosing between two items, a third item is introduced that causes you to switch your preference between the first two items [11]. The decoy effect is completely irrational: If you choose between two options: Item A is better than Item B. But if you choose between three options, suddenly Item B is better than Item A. Logically, this doesn't make sense. If $A$ is superior to $B$, then A should still be superior to $\mathrm{B}$ even if $\mathrm{C}$ is added.

Another example, if we ask someone if he/she like dogs or cats more, and one say they like dogs best; then asking whether they like dogs, cats, or mice more shouldn't make them say they like cats best (since dogs are already better than cat, they said). If dogs are better than cats when there are two options, dogs are still better than cats when there are three options [12]. Sadly, human mind doesn't always think rationally. There are times when our decision is biased and uncontrolled. Thus, when we are making choices, we make such an irrational switch all the time. What's going on withour mind, folks?

\section{A Famous Example of Decoy Effect}

As stated in Hendricks [12], MIT Professor Dan Ariely noticed something strange on The Economist subscription page. The magazine offered three subscription offers at the following prices; see Fig. 1.

\begin{tabular}{|c|c|}
\hline Economisticom & SUBSCRIPTIONS \\
\hline OPANION & \multirow{5}{*}{$\begin{array}{l}\text { Welcome to } \\
\text { The Economist Subscription Centre } \\
\text { Pick the type of subscription you want to buy } \\
\text { or renew. }\end{array}$} \\
\hline WORLD & \\
\hline BUSANESS & \\
\hline FBLUNCE \& ECONOUACS & \\
\hline SCFENCE \& TECHNOLOGY & \\
\hline PEOPLE & \multirow{4}{*}{$\begin{array}{l}\text { Economist.com subscription - US } \$ 59.00 \\
\text { One-year subscription to Economist.com. } \\
\text { Includes online access to all articles from } \\
\text { The Economist since } 1997 \text {. }\end{array}$} \\
\hline BOOKS \&ARTS & \\
\hline IURKETS \& DATA & \\
\hline \multirow[t]{3}{*}{ DNERSIOIIS } & \\
\hline & $\begin{array}{l}\text { Drint subscription - US } \$ 125.00 \\
\text { One-year subscription to the print edition } \\
\text { of The Economist. }\end{array}$ \\
\hline & $\begin{array}{l}\text { Print \& web subscription - US } \$ 125.00 \\
\text { One-year subscription to the print edition } \\
\text { of The Economist and online access to all } \\
\text { articles from The Economist since } 1997 \text {. }\end{array}$ \\
\hline & \\
\hline
\end{tabular}

Fig. 1. Famous example of a decoy marketing.

Ariely did an experiment with his students. He split them into two groups: Group 1 was offered two options: a web-only subscription and a print + web subscription, while Group 2 was offered all three options: a web-only subscription, a print-only subscription and a print + web subscription. Here's what each group chose: Group 1 (when two options were presented): $68 \%$ of people chose web only, and $32 \%$ of people chose both print and web, while Group 2 (when three options were presented): $16 \%$ chose web only, $0 \%$ chose print only, and $84 \%$ chose both. Amazing yet intrigueing results, right? was useless was useless in the sense that nobody wanted it. But it wasn't useless in the sense that it helped people figure out what they wanted... We actually don't know our preferences that well, and because we don't know our preferences that well, we're susceptible to all the influences from external forces." It is clear that the only function of the third option, namely the decoy, is to guide people toward the most beneficial option according to The Economist, but not necessarily the most beneficial to its subscriber. However, people still fall into this old trick.

Hendricks gives an example that decoy canalso affect our political views [12]. He said that while Barack Obama was in office, we may not have liked George W. Bush. But now that Donald Trump is in office, we probably like Bush a little more now. In neither case do we like Donald Trump. That's because Trump is the decoy. Simply adding Donald Trump to the set doesn't change our views of either Obama or Trump, but it may shift our opinion of Bush. And this is supported by The CNN poll conducted by SSRS which found that 61 percent of Americans polled view Bush favorably and just 33 percent view him unfavorably [11].

\section{E. How The Decoy Works}

According to Hendricks [12], Decoy works best when there are three options to choose, namely a target, acompetitor, and a decoy. Target is the choice someone wants you to make, whether that is a company who sell product, a waiter or seller of a product/service, a real estate agent, a political strategist, or any person or group (or circumstance) responsible for setting up your choice options; including a marketer and an advertiser. Competitor is the option that is up against the target. This is what they want you not to choose, even if you previously favorites it. Last one, the decoy, is what will (hopefully) change your choice from the competitor into the target when it is added into the choice-sets.

Decoys operate at our subconscious level. A decoy changes how we value the target. Hendricks also explains that decoy reframes the way we approach the decision by changing which attributes of the choices we focus on [12]. Whereas without a decoy, we evaluate multiple product attributes at the same time, with a decoy, we'll instead focus on only one attribute at a time. The way we evaluate that attribute will change: instead of comparing attributes between products, we evaluate each product against our own identity and values. Instead of asking whether or not the product is inferior or superior for multiple attributes at once, we'll now ask whether a product is superior or inferior on one attribute at a time. The decoy shifts a comparison among products to a consumer-product comparison. Adding a decoy to a choice set literally changes the entire context by which we made a decision.

\section{F. Decoy Effect in Digital Marketing and eWOM}

Huber commented that with the emerging of digital marketplace the decoy effect could very well exist in real life situations [10]. In 2014, they published a comment in which they reflect on the documentation of the decoy effect by academics for the past 32 years. They agree to an extent that the decoy effect does not happen often in market place choices as very few completely dominated decoys continue to exist in 


\section{B. Samples and Experiment Design}

the marketplace. However they do posit that the rarity of dominated alternatives may be reduced in the emerging digital marketplace.

"One need only visit Amazon.com, where almost every choice includes a price and a reviewer's 1-5 "star" rating", they said. These 'star rating' scales on Amazon.com reflect the average customer review for a respective product. These reviews can be regarded as eWOM which is a form of social proof that regularly influences our decision making process. Cialdini [13] mentioned that experiments have shown that humans rely heavily on other people around them to give them cues on how to think, feel and act. People are especially prone to look for social proof in uncertain or unfamiliar situations [3].

Huber [9] believe that in a digital marketplace, the possibility of decoy exploitation exist. There, choice sets exist with $2 \times 2$ attribute levels. Something which Frederick [14] argue does not exist in ordinary purchases situations. Huber, Payne, and Puto posit that the decoy effect may occur on digital marketplace more easily as all choice sets contain two variables: a price and a reviewers rating. Until now academics have not provided empirical evidence that review ratings can be used create a decoy effect, therefore need to be tested on an empirical level [3].

This research aims to prove that decoy effect can exist on a digital market place in Indonesia, namely Shopee. We assume that for a low involvement product, people esp. Indonesian citizen prefer to buy product with cheapest price as long as it has the same features with the higher one. And as explained earlier, clearly consumers are influenced more by negative reviews than positive ones. Not only does a negative review influence buying intentions for certain product but it also reduces brand attitude. Translating this to a decoy setting in which decoy and target share the same brand name, it is very plausible that decoy effect is mitigated by negative review [3].

As a digital person ourselves, we are more likely to watch Youtube video that has $1 \mathrm{k}+$ views rather than just 100 views. Again, people tend to use social proof in their decision process to reduce uncertainty. In this case, we follow the herd: if many visitors seem to watch that video, we think that the video must be really good. And just like YouTube, marketplaces like Shopee also shows the amount of reviews in their search results. As the decoy is meant to increase sales of the target and not itself, there will only be a few reviews for this product.

\section{RESEARCH METHODS}

\section{A. Theoretical Framework}

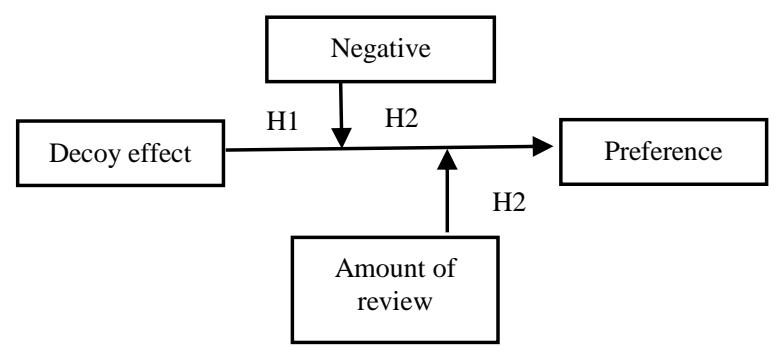

In order to test whether decoy has effect to customers' preference, mitigated by negative review and amountof review, we set up a framed field experiment. We collect data from 220 online citizen science. According to Wikipedia, citizen science is a thriving practice that involves public participation in activities and processes behind a scientific research. Through citizen science, people share and contribute to data monitoring and collection programs. As mentioned in Ullrich [15], during the last few years, the field of citizen science has expanded even more rapidly with the development of smartphones, allowing more information to be shared through digital media. After answering some demographic questions such as age and gender, respondents are then presented with such a prefabricated Shopee search results with a target item, a competitor item, and a decoy (depending on the experiment question).

We are using Repeated measures/within groups type of experiment, where the same participants take part in each condition of the independent variable. In order to compare customer preferences before/after decoy, respondents are being asked five times with the same question under diffferent treatments. We avoid using high involvement product as our object, such as smartphone or television, as the decision process for this kind of product is much more complex compared to low involvement products such as ice cube tray or trash bin. Ones who want to buy TV, for example, consider much more dimensions than just price/review rating [14].

Table I will show an overview of our experiment design. The first question acts as our control where no decoy is introduced yet, and the answer of this question will be compared to customer's preference after decoy exists to test whether the decoy effect exists in digital market. Treatment 1 is used to measure the effect of negative. We are using a car trash bin as an object of experiment and the products/brands are real (you can find them in marketplace Shopee). Here we set so as competitor has cheaper price, and our target has higher price. Decoy is a product with similar brand/type as competitor but with a little bit higher price compare to competitor, but not as high as the target.

TABLE I. OVERVIEW OF EXPERIMENT DESIGN

\begin{tabular}{|l|l|l|l|l|l|l|}
\hline \multirow{2}{*}{ Treatment } & \multicolumn{6}{|c|}{ Type } \\
\cline { 2 - 7 } & $\begin{array}{c}\text { Target } \\
(\boldsymbol{T})\end{array}$ & $\begin{array}{c}\text { Competitor } \\
(\boldsymbol{C})\end{array}$ & $\begin{array}{c}\text { Decoy } \\
\text { Negative }\end{array}$ & $\begin{array}{c}\text { Decoy } \\
\text { Positive }\end{array}$ & $\begin{array}{c}\text { Decoy } \\
\text { Minimum }\end{array}$ & $\begin{array}{c}\text { Decoy } \\
\text { Maximum }\end{array}$ \\
\hline Control & $\mathrm{x}$ & $\mathrm{x}$ & & & & \\
\hline $\begin{array}{l}\text { Treatment } \\
1\end{array}$ & $\mathrm{x}$ & $\mathrm{x}$ & $\mathrm{x}$ & & & \\
\hline $\begin{array}{l}\text { Treatment } \\
2\end{array}$ & $\mathrm{x}$ & $\mathrm{x}$ & & $\mathrm{x}$ & & \\
\hline $\begin{array}{l}\text { Treatment } \\
3\end{array}$ & $\mathrm{x}$ & $\mathrm{x}$ & & & $\mathrm{x}$ & \\
\hline $\begin{array}{l}\text { Treatment } \\
4\end{array}$ & $\mathrm{x}$ & $\mathrm{x}$ & & & & $\mathrm{x}$ \\
\hline Price & 50000 & 33000 & 38250 & 38250 & 38250 & 38250 \\
\hline $\begin{array}{l}\text { Review } \\
\text { Rating }\end{array}$ & 5 star & 4,5 star & 2 star & 5 star & 4 star & 4,5 star \\
\hline $\begin{array}{l}\text { Products } \\
\text { Sold }\end{array}$ & $\begin{array}{l}166 \\
\text { sold }\end{array}$ & 160 sold & 160 sold & $\begin{array}{l}487 \\
\text { sold }\end{array}$ & 18 sold & $1,6 \mathrm{k}$ sold \\
\hline
\end{tabular}

Fig. 2. Theoretical framework. 
the controlled question where no decoy item was present, a

\section{Treatment Design}

Fig. 3 displays treatment design with rating and price as its dimensions. Target item is a car trash bin being sold at $\mathrm{Rp}$. 50.000,-, while competitor item is priced cheaper: Rp.33.000,-Both items can be found on marketplace Shopee and therefore are real products/carry real brand names. Target item has a high review rating of 5 stars out of 5 and competitor item has 4, 5 stars. Fig. 4 shows treatment design with number of products sold and price as dimensions. Target and competitor has almost similar number of products sold, however decoy in Treatment 4 has most (maximum) number of product sold, whereas decoy in Treatment 3 has least (minimum) number of product sold.

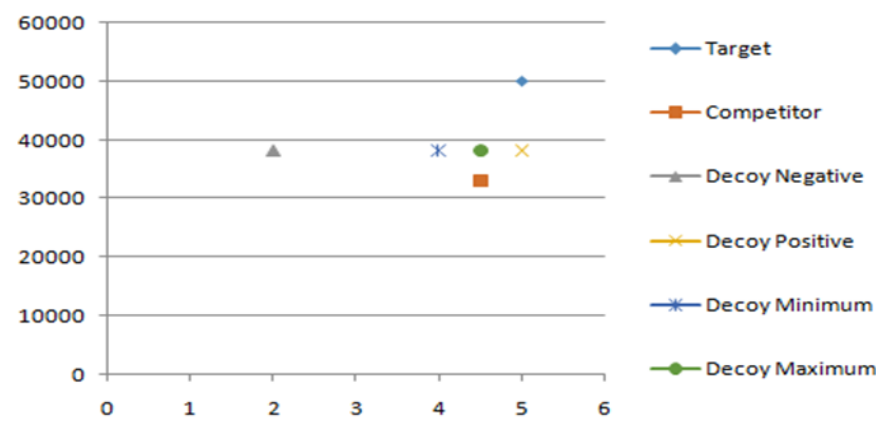

Fig. 3. Treatment design with rating and price as dimensions.

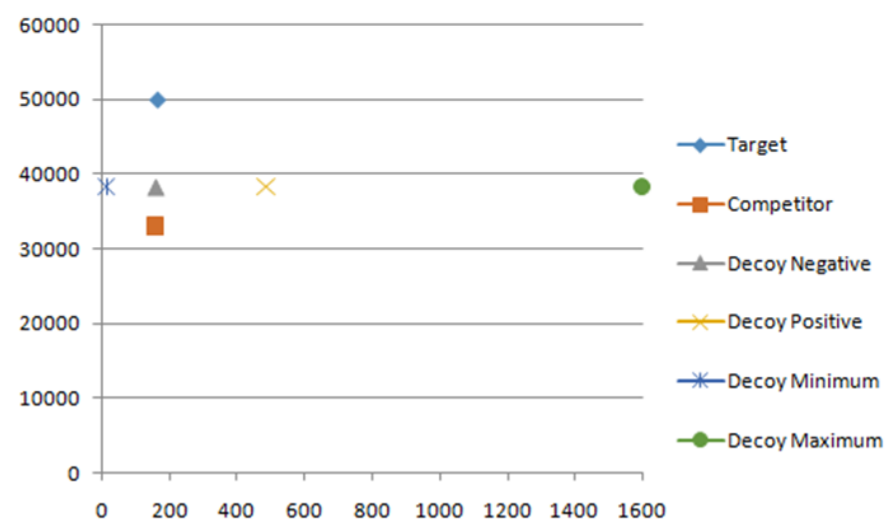

Fig. 4. Treatment design with number of product sold and price as dimensions.

Once again, note that decoy has similar feature (and actually is the same product) as the competitor, but being sold in different store with a bit higher price that the competitor's. This is designed as such, to see whether there is a shift in Indonesian's citizen science preference as a result of the decoy effect in digital marketplace.

\section{RESULTS AND DISCUSSION}

\section{A. Experiment Results}

In this research, all 220 respondents are participated in the online questionnaire experiment. There are actually 250 responses of our questionnaires, however, some responses are doubled (two responses come from the same person), thus we delete 30 double responses. After deletion, there are 220 respondents left: 99 males and 121 females. Age of respondents ranges from 15 to $>35$ years old. Fig. 5 shows the amount of respondents who prefer target than competitor. In total of $45.45 \%$ of the respondents chose the target item.

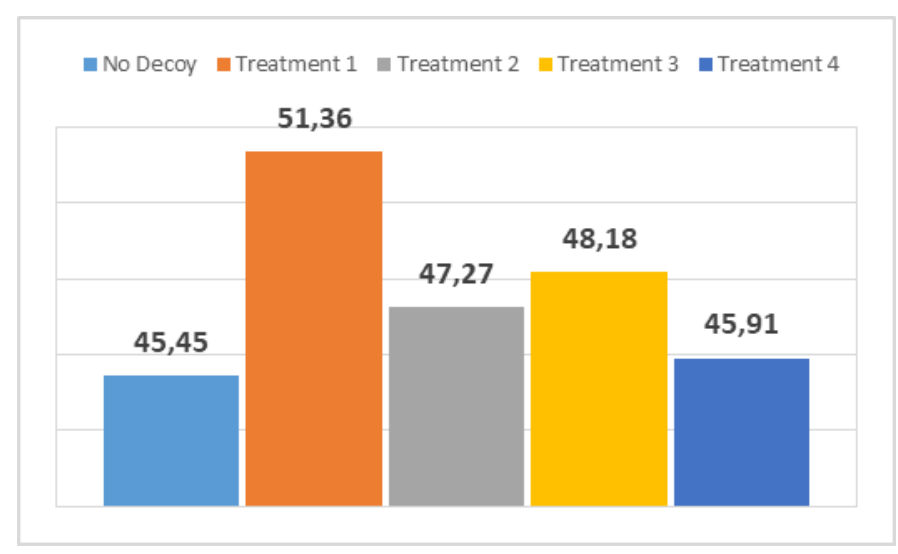

Fig. 5. Customer Preferences on the target item.

Since our independent variable 'customer preference' is a dichotomous variable (it has only two choices), respondents can only choose either the target item or the competitor item. A dichotomous variable by definition is not normally distributed, thus violates the assumptions of normally distributed data needed for parametric test. As a result, we use non-parametric Wilcoxon test as an alternative of paired sample t-test. See Table II for the Wilcoxon test result we got from SPSS.

TABLE II. WILCOXON TEST RESUlTS

\begin{tabular}{|l|l|l|l|l|}
\hline \multirow{2}{*}{} & \multicolumn{4}{|c|}{ Test Statistics $^{\mathrm{a}}$} \\
\cline { 2 - 5 } & $\begin{array}{c}\text { Decoy } \\
\text { Negative-No } \\
\text { Decoy }\end{array}$ & $\begin{array}{c}\text { Decoy } \\
\text { Positive- } \\
\text { No Decoy }\end{array}$ & $\begin{array}{c}\text { Decoy } \\
\text { Minimum- } \\
\text { No Decoy }\end{array}$ & $\begin{array}{c}\text { Decoy } \\
\text { Maximum- } \\
\text { No Decoy }\end{array}$ \\
\hline Z & $-2,030^{\mathrm{b}}$ & $-0,686^{\mathrm{b}}$ & $-1,225^{\mathrm{b}}$ & $-0,164^{\mathrm{b}}$ \\
\hline $\begin{array}{l}\text { Asymp.Sig. } \\
\text { (2-tailed) }\end{array}$ & 0,042 & 0,493 & 0,221 & 0,869 \\
\hline \multicolumn{4}{|c|}{$\begin{array}{c}\text { a. Wilcoxon Signed Ranks Test. } \\
\text { b. Based on positive ranks. }\end{array}$}
\end{tabular}

We recap the result of this Wilcoxon test on Table III, to provide a clearer picture on our decision process.

TABLE III. OVERVIEW OF WILCOXON TEST RESUlTS

\begin{tabular}{|l|l|l|}
\hline \multirow{2}{*}{} & \multicolumn{2}{|c|}{ Test Statistics $^{\mathbf{2}}$} \\
\cline { 2 - 4 } & \multicolumn{2}{|c|}{$\boldsymbol{p}$} \\
\hline Control vs Decoy Negative & -2.030 & $0.042^{*}$ \\
\hline Control vs Decoy Positive & -0.686 & 0.493 \\
\hline Control vs Decoy Minimum & -1.225 & 0.221 \\
\hline Control vs Decoy Maximum & -0.164 & 0.869 \\
\hline
\end{tabular}

Fig. 6 and fig. 7 shows preferences based on gender, and table 4 shows the result of Kruskal Wallis Test on gender preferences. 
This result supports the earlier research done by Roks [3],

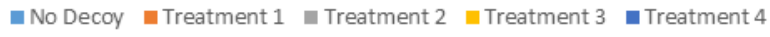
\begin{tabular}{l|l|l|l|l|}
\hline 44,44 & 53,54 & & & \\
\hline & 45,45 & 47,47 & 47,47 \\
\hline & & & \\
\hline & & \\
\hline & & \\
\hline
\end{tabular}

Fig. 6. Male customer preference.

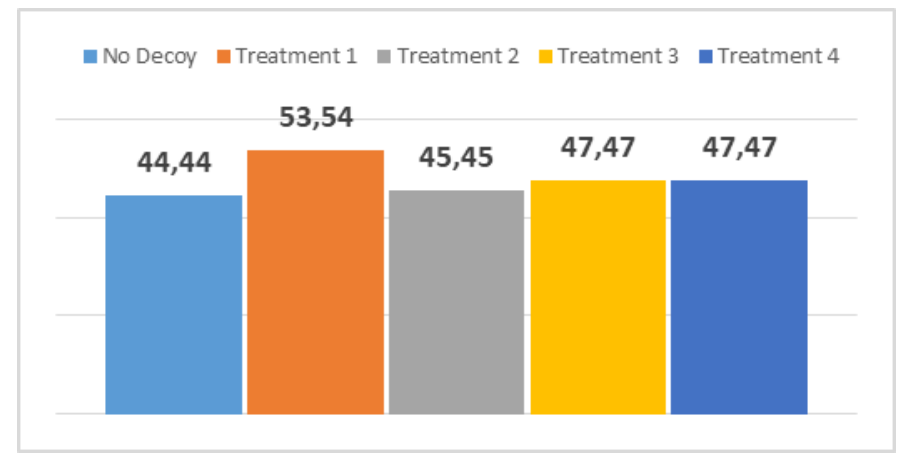

Fig. 7. Female customer preference.

TABLE IV. TEST STATISTICS

\begin{tabular}{|l|l|l|l|l|l|}
\hline & \multicolumn{1}{|c|}{$\begin{array}{c}\text { No } \\
\text { Decoy }\end{array}$} & $\begin{array}{c}\text { Treatment } \\
\mathbf{1}\end{array}$ & $\begin{array}{c}\text { Treatment } \\
\mathbf{2}\end{array}$ & $\begin{array}{c}\text { Treatment } \\
\mathbf{3}\end{array}$ & $\begin{array}{c}\text { Treatment } \\
\mathbf{4}\end{array}$ \\
\hline $\begin{array}{l}\text { Chi- } \\
\text { Square }\end{array}$ &, 074 &, 338 &, 238 &, 036 &, 177 \\
\hline df & 1 & 1 & 1 & 1 & 1 \\
\hline $\begin{array}{l}\text { Asymp. } \\
\text { Sig. }\end{array}$ &, 786 &, 561 &, 626 &, 850 &, 674 \\
\hline
\end{tabular}

b. Grouping Variable: Gender (male, female)

\section{B. Discussions}

Our research results show that in our experiment, the decoy effect does exist in digital marketplace Shopee. Online buyers can be influenced to change their preference towards low involvement products like a car trash bin by introducing a decoy which is similar to the competitor but has negative review from previous buyers (shown by a low star rating in Shopee).These online stores in Shopee display a review ratings in their search results as a form of social proof for customers to help making decisions.

Secondly, data does imply that a negative review can have moderating effect on respondent's decision making process. This is shown in Table III, where the $p$ value for Control vs Decoy Negative is $<0.05$. As for gender preference, based on our experimental results shown in table 4 there is no significant different between male and female on online product purchasing preferences all the Asymp. Sig value is $>0.05$. where he mentioned that behavioural theories such as risk and loss aversion can explain why a decoy with a negative review rating is less effective than a review with an average review rating. Although academic research suggests that males and females respond differently to risk, the data does not show any gender differences. However it does seem logical that a decoy with a negative review would signal a high risk or possible loss.

\section{REFERENCES}

[1] Anastasia, Types of Marketing Strategies that Attract Customers, December 8, 2016, [Online] Retrieved October 31, 2019, from cleverism.com https://www.cleverism.com/types-marketing-strategiesattract-customers/.

[2] A. Dimoka, Y. Hong, and P.A. Pavlou, "On product uncertainty in online markets, Theory and evidence," MIS Quarterly: Management Information Systems Journal, vol. 36, no. 2, pp. 395-426, June 2012.

[3] T. Roks, The Decoy Effect versus eWOM, Rotterdam, 2015.

[4] J.A. Chevalier and D. Mayzlin, "The effect of word of mouth on sales: Online book reviews", Journal of marketing research, vol. 4, no. 3, pp. 345-354, 2006.

[5] P. Resnick and R. Zeckhauser, "Trust among strangers in internet Economics of the Internet and E-commerce, vol. 11, no. 2, pp. 23-25, 2002 .

[6] T. Hennig-Thurau, K.P. Gwinner, G. Walsh, and D.D. Gremler, "Electronic word-of-mouth via consumer-opinion platforms: what motivates consumers to articulate themselves on the internet?," Journal of interactive marketing, vol. 18, no. 1, pp. 38-52, 2004.

[7] T. Hennig-Thurau, G. Walsh, "Electronic Word-of-Mouth: Motives for and Consequences of Reading Customer Articulations on the Internet", International Journal of Electronic Commerce, vol. 8, no. 2, pp. 51-74, 2003.

[8] R.D. Luce, Individual Choice Behavior: A Theoretical Analysis, New York: Wiley, 1959.

[9] J. Huber, J.W. Payne, and C. Puto, "Adding asymmetrically dominated alternatives: Violations of regularity and the similarity hypothesis," Journal of consumer research, pp. 90-98, 1982.

[10] J. Huber, J.W. Payne, and C.P. Puto, "Let's Be Honest About the Attraction Effect," Journal of Marketing Research, vol. 51, no. 4, pp. 520-525, 2014

[11] M. Gstalter, Poll: Majority have favorable view of George W. Bush, January 22, 2018, [Online] Retrieved October 29, 2019, from thehill.com: https://thehill.com/blogs/blog-briefing-room/370186-pollmajority-have-favorable-view-of-george-w-bush.

[12] K. Hendricks, "The decoy effect: Why you make irrational choices every day (without even knowing it)," February 12, 2018.

[13] R.B. Cialdini, "Harnessing the science of persuasion," Harvard Business Review, vol. 79, no. 9, pp. 72-81, 2001.

[14] S. Frederick, L. Lee, and E. Baskin, "The limits of attraction," Journal of Marketing Research, vol. 51, no. 4, pp. 487-507, 2014.

[15] C. Ullrich "Citizen Science: Encyclopedic Entry", National Geographic Online Magazine, May 16, 2012, [Online] Retrieved October 31, 2019, from nationalgeographic.org https://www.nationalgeographic.org/encyclopedia/citizen-science/. transactions: Empirical analysis of ebay's reputation system," The 